\title{
Quantification of surface runoff in Patiala-Ki-Rao watersheds using modified NRCS model: a case study
}

\author{
Sumita Chandel* and M. S. Hadda \\ Department of Soil Science, Punjab Agriculture University, Ludhiana-141004 (Punjab), INDIA \\ *Corresponding author: sumi.chandel@gmail.com \\ Received: December 2, 2016; Revised received: February 25, 2017; Accepted: August 5, 2017
}

\begin{abstract}
Quantification of the surface runoff in a watershed is of vital importance for solution of many water resource problems. It can be quantified by employing large number of estimation approaches. Of these, SCS-CN approach is quite simple effective and requires less number of parameters. Thus, the objective of the study was to employ soil conservation service-curve number (SCS-CN) approach and their modifications to estimate surface runoff for Patiala -Ki-Rao watershed, district SAS, Nagar, Punjab and to choose the best model of the 8-different employed models. Soil moisture retention parameter was characterised and optimised by using the descriptive statistics and later used in the models. The mean and median valueof soil moisture retention parameter was $47.2 \mathrm{~mm}$ and $35.9 \mathrm{~mm}$ for June to September months and 35.4 to $30.8 \mathrm{~mm}$ for October to March months. The models were evaluated on the basis of Root Mean Square Error (RMSE), Nash- Scutcliffe Efficiency (NSE), Coefficient of Determination $\left(\mathrm{R}^{2}\right)$ and Per cent Bias (PB). Of the evaluated and tested models, NRCS model (M5) performed best with the highest score of 32 and 31 by employing mean andmedian values of soil moisture retention parameter in Patiala-Ki-Rao watersheds over the other models. Further, the results of the study suggested in evaluating the performance of NRCS model (M5) in other treated micro-watersheds at Patiala-Ki-Rao, Punjab, over the control.
\end{abstract}

Keywords: Model, Nash Scutclifee Efficiency, Punjab, Root mean square error, Watershed

\section{INTRODUCTION}

Quantification of surface runoff in a watershed is of vital importance for solution of many water resource problems such as design of irrigation and drainage works, rainwater harvesting, planning and designing of soil and water conservation works and understanding surface hydrology. Transformation of rainfall into the runoff is very complex, non-linear, dynamic and shows special and temporal variability, which is affected by many other parameters and inter-related physical factors (Meher, 2014).

Runoff and soil erosion by water is a serious problem in Patiala-Ki-Rao watersheds, where 20 to 45 per cent annual rainfall is lost as surface runoff (Hadda $e t$. al., 2000). Rainfall variability is more in the winter monthsover the summer months in the area (Singh, 2014). As each watershed is unique in its characteristics; it becomes costly and labour intensive to install gauging stations to monitor runoff. Thus, analysis of rainfall-runoff relationship assumes significance in the area from quantification of surface runoff point of view in the watersheds.

A large number of approaches has been used for the estimation of the surface runoff including the original SCS-CN model (M1), inspired and modified modelsM2 (Woodward et. al., 2003), M3 (Jain et. al., 2006), M4 (Cazier and Hawkins, 1984), modified initial abstraction (Ia) in the NRCS model, M5 (Ajmal et. al.,2016), newly proposed models (M6, M7 and M8, Ajmal and Kim, 2015). Among them, soil conservation service curve number approach for estimation of surface runoff from the given rainfall event is quite promising (Ponce and Hawkins, 1996). This approach is quite simple, efficient and requires less number of parameters, well documented response for a soil and land use, and applicable in both gauged and ungauged watersheds (Ajmal and Kim, 2015). In spite of this, many studies documented that the ratio of initial abstraction to maximum potential retention $(\lambda=\mathrm{Ia} / \mathrm{S})$ which is equal to 0.2 in SCS-CN method, is ambiguous and represents very unrealistic results (Woodward et. al., 2003, Mishra et. al., 2005, Shi et. al., 2009). Therefore, these models must be calibrated by using field measurements (Papanicolaou et. al., 2008). As these models are highly complicated and non-linear, so difficulty exists in modelling of runoff. Thus, an accurate and simple model that can be employed to model the runoff generation process is of immediate concern (Lin and Wang 2007 and Vaezi et al., 2010).

Thus, the objective of the study is to carry out and choose the best model of the 8-different employed models including the original SCS-CN model (M1), inspired and modified models (M2, M3, M4), modified Ia in the NRCS model (M5), newly proposed models (M6, M7 and M8) for the estimation of the surface 


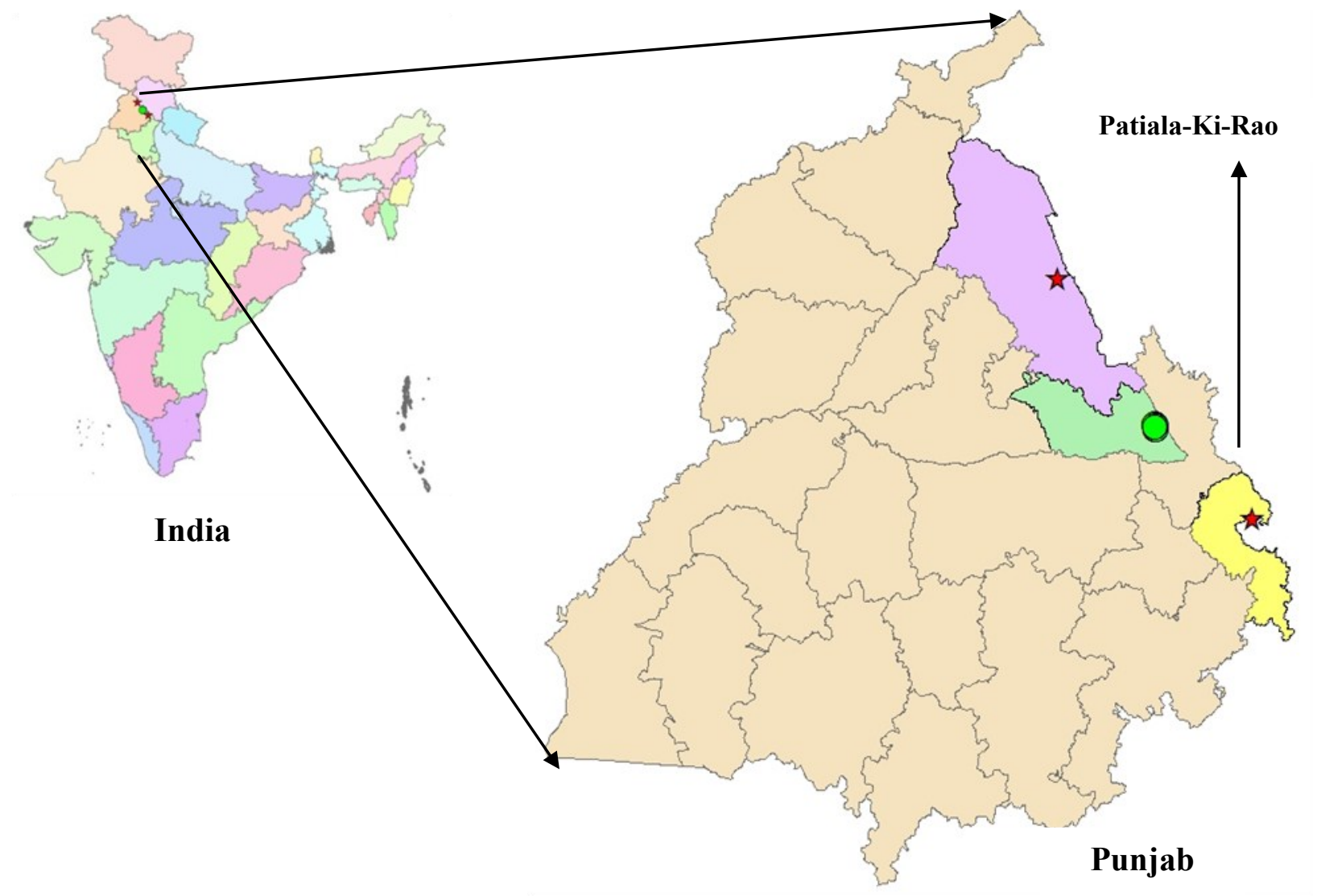

Fig. 1. Location map of Patiala-Ki-Rao watershed.

runoff depth.

\section{MATERIALS AND METHODS}

Study area: The Study was carried out in Patiala-Ki Rao watershed, situated in the foothills of the Shivaliks (Kandi area), SAS Nagar $\left(30^{\circ} 40^{\prime}\right.$ to $32^{\circ} 30^{\prime} \mathrm{N}$ latitude and $75^{\circ} 30^{\prime}$ to $76^{\circ} 40^{\prime}$ E longitude) Punjab, at an elevation of $415 \mathrm{~m}$ above mean sea level (Fig 1). The climate of the area is semi-arid (Thornwaite, 1948), which receive about $1090 \pm 340 \mathrm{~mm}$ of rainfall annually. The rainfall distribution is bimodal with most of the rainstorms occur during the months of June to September (75-80 per cent), remaining occurs in the months of October to March (20-25 per cent; Fig 2). The rainstorms received in the area vary in number from 20 to 30 , of which 8 to 12 produce runoff and overland flow (Hadda et al., 2001). Higher runoff and soil erosion occur during the high intensity and short duration rainstorms received in the area. The soils of the area remain dry for 4-5 months in a year and it qualified for ustic soil moisture regime (Soil Survey Staff, 1975). The watershed comprising Shivalik deposits ie alluvial detritus derived from the sub-aerial waste of the mountains, dissected by the ephemeral streams and rivers. The catchment area of the watershed is 2.9 ha with mean slope of 32.1 per cent. The geomorphic characteristics of the watershed are given in the Table 1 . The monthly distribution of rainfall (mm) pattern over the year $(1982-1999)$ at Patiala-Ki -Rao watershed is shown in the Fig. 2. This indicated the maximum rainfall occurred in the months of July followed by August, September and June. However, the rainfall is distributed in the form of bimodal from June to September and October to March in the watershed.

Runoff-runoff model: Brief description of the models employed to compute runoff is discussed below.

Soil conservation service -curve number: The SCSCN (SCS, 1972) method is based on a water balance

$$
\mathrm{P}=\mathrm{Ia}+\mathrm{F}+\mathrm{Q}
$$

and two fundamental hypotheses which can be expressed as:

Where, $\mathrm{P}$ is precipitation in $\mathrm{mm}$, Ia is the initial abstraction in $\mathrm{mm}$, depression storage and infiltration that must be satisfied,before any runoff can occur, F, is cumulative infiltration excluding Ia and $\mathrm{Q}$ is the direct runoff in $\mathrm{mm}$. The general form of the model can be expressed as:

$$
\mathrm{Q}=\frac{(\mathrm{P}-\mathrm{Ia})^{\mathrm{2}}}{(\mathrm{P}-\mathrm{Ia}+\mathrm{S})}
$$

$$
\mathrm{Ia}=\lambda \mathrm{S}
$$


Table 1. Geomorphic characteristics at Patiala-Ki-Rao watershed.

\begin{tabular}{lll}
\hline S.N. & Characteristics & Watershed \\
\hline 1. & Drainage area (ha) & 2.9 \\
2. & Length of main channel (m) & 186.0 \\
3. & Length of main valley $(\mathrm{m})$ & 30.6 \\
4. & Main channel slope $(\%)$ & 11.3 \\
5. & Shape factor & 2.1 \\
6. & Drainage density $\left(\mathrm{km} \mathrm{km}^{-2}\right)$ & 12.0 \\
7. & Relief ratio & 0.2 \\
8. & Watershed slope $(\%)$ & 32.1 \\
\hline
\end{tabular}

Source: Adapted from Hadda et al. (2002)

Ia is taken as the fraction of $S$, ie 20 per cent of the maximum potential retention, i.e.

Where $\lambda$ is 0.2

Further, models employed to compute runoff are enlisted in Table 2. About 217 rain storm events were received in 18 years (1983-1999). These were analysed to obtain rainfall-runoff $(\mathrm{P}-\mathrm{Q})$ relationship. The rainfall is the most important descriptor of the meteorological characteristics. It is used for ordering the P-Q (Ajmal and Kim, 2015, Woodward et al., 2003). Runoff was computed by employing different models enlisted in Table 2 (M1-M8)and performance evaluation was made by statistical tools comparing the root mean square error (RMSE), coefficient of determination $\left(\mathrm{R}^{2}\right)$, Nash-Scutcliffe Efficiency (NSE) and per cent bias (PB). It was followed by the total ranking scores for all the performance indices. The soil moisture retention parameter (S-parameter) was characterised through the descriptive statistics, computed for both summer and winter season by employing equation 5 , due to bimodal distribution of the rainfall in the area.

Efficiency of model: For better calibration and validation of hydrological modelling, combination and comparison of different efficiency criteria was used. Efficiency criteria used were root mean square error (RMSE), coefficient of determination $\left(\mathrm{R}^{2}\right)$, NashScutcliffe Efficiency (NSE) and percent biasness (PB). These were used as indices of the agreement between the computed and observed in equation 14, 15, 16 and 17.values of the runoff. They can be expressed as:

Table 2. Models employed for estimation of surface runoff in Patiala-Ki-Rao watershed.

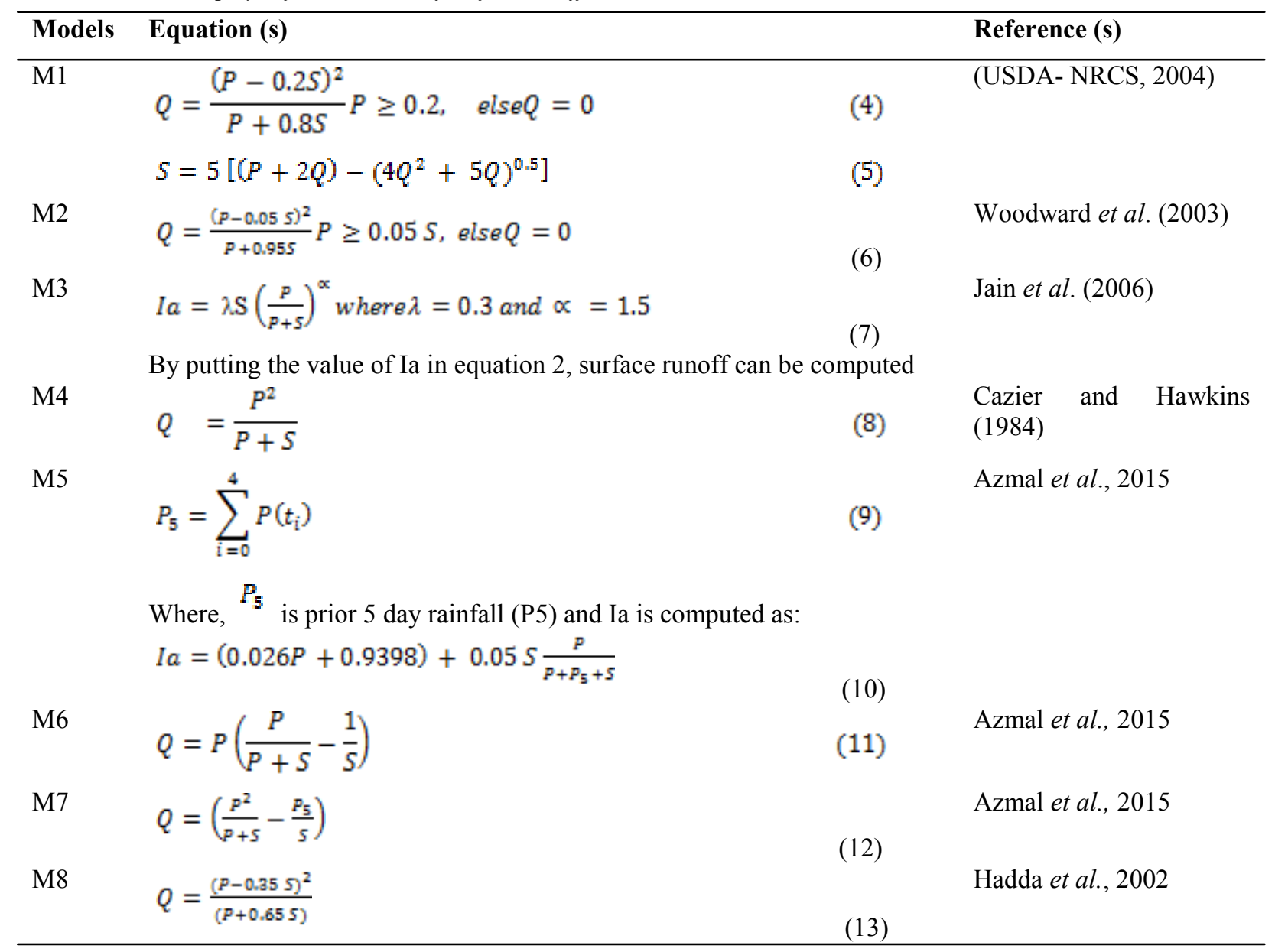

Where, Q, P, Ia and S are direct runoff, total rainfall, initial abstraction and potential maximum retention in mm. 


$$
\begin{aligned}
& \mathrm{RMSE}=\sqrt{\frac{1}{\mathrm{~N}} \sum_{\mathrm{i}=1}^{\mathrm{N}}(\mathrm{Qo}-\mathrm{Qc}) \mathrm{i}^{2}} \\
& \mathrm{NSE}=1-\left[\frac{\left.\sum_{\mathrm{i}=1}^{\mathrm{n}}(\mathrm{Q} \text { oi-Qei) })^{2}\right)}{\sum_{\mathrm{i}=1}^{\mathrm{n}}\left(\mathrm{Qoi}-\mathrm{Q} o(\text { mean })^{2}\right.}\right]
\end{aligned}
$$

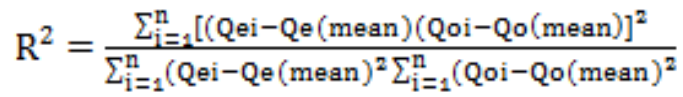

$$
\begin{aligned}
& \mathrm{PB}=\left[\frac{\sum_{\mathrm{i}=1}^{\mathrm{n}}\left(\mathrm{Q}_{\mathrm{oi}}-\mathrm{Q}_{\mathrm{ei}}\right)}{\sum_{\mathrm{i}=1}^{\mathrm{n}}\left(\mathrm{Q}_{\mathrm{oi}}\right)}\right] \times 100
\end{aligned}
$$

Where, Qoi, Qei, Qo (mean) and Qe (mean) are observed, estimated, mean of observed and mean of estimated runoff storm events i to n, respectively. Smaller, the RMSE of any particular model better will be the model to estimate runoff. The Optimum value of RMSE is 0 . The value for NSE ranged between - to 1 with $\propto$ optimum value 1 . If the NSE $>0.50$, the model can be considered satisfactory (Moriasi et. al., 2007). However, according to Ritter and Munoz-Carpene (2013), if NSE $>0.65$, the hydrological model can be considered satisfactory. For $\mathrm{R}^{2}$, a model can be considered satisfactory if value of $\mathrm{R}^{2}>0.62$ (DiazRamirez et. al., 2011). The PB, represent the tendency of the model to underestimate or overestimate values, and zero represent the perfect fit of the model. The positive $\mathrm{PB}$ value formodel indicates underestimation and vice-versa. In addition to this, quantitative statistical goodness of fit evaluation can also be carried out by using scatter plot comparison of the observed and estimated runoff (Fig 4).

The evaluation criteria for different performance ratings using RMSE-based model limitation, NSE, $\mathrm{R}^{2}$, and PB is given in the Table3. The quantitative assessment of the models was made and graded on the basis of the statistics obtained from the data. The rank of 1 to 8 were assigned to show the RMSE, NSE, $\mathrm{R}^{2}$ and PB values were in the ascending order (lowest to highest), corresponding score was provided, for example, rank 1 showed the best performance therefore the highest score of 8 was assigned to it. Whereas for rank 8 , score 1 was assigned.

\section{RESULTS AND DISCUSSION}

The soil moisture retention parameter (S) and its descriptive statistics are given in Table 4 . The mean and median S parameter was $47.2 \mathrm{~mm}$ and $35.9 \mathrm{~mm}$ respectively for June to September, whereas for October to March it was $35.4 \mathrm{~mm}$ and $30.8 \mathrm{~mm}$ respectively. The mean, median, SD and CV (\%) of S parameter were higher in magnitude from June to September over October to March. The per cent CV in June to September was 1.54 times over the October to March. On the basis of standard deviation (SD) and coefficient of variance (CV), mean and median $\mathrm{S}$ parameter for June to September was utilised for the estimation of the surface runoff, as indicated through the higher SD (40.1) and CV (84.9\%).

The estimated runoff varied differently through different employed rainfall-runoff models ie M1 to M8 and their relevant statistics. The observed mean rainfall received per storm for Patiala-Ki-Rao watershed varied from minimum $38.6 \mathrm{~mm}$ to maximum $85 \mathrm{~mm}$ over the years (Table 5). Correspondingly, the observed runoff varied from minimum 17.3 to maximum $42.2 \mathrm{~mm}$ over the years. The estimated runoff, which approached closer to the observed runoff ie 25.6 and $27.5 \mathrm{~mm}$ as indicated through the model M5 and M4 respectively. In India, Panday et al. (2003) reported that maximum and minimum error between the observed and estimated runoff depths were 68.3 and 3.3 per cent, respectively. Thus, the model M5 and M4 showed better capability in terms of runoff estimation, and it was confirmed by different goodness of fit procedures through different models (Table 6 and 7).

Table 3. Rating criteria using RMSE-based model limitation, NSE, $\mathrm{R}^{2}$, and PB .

\begin{tabular}{lllll}
\hline Rating & RMSE-based model limitation & NSE & $\mathbf{R}^{2}$ & PB (\%) \\
\hline Very good & $\mathrm{SD} \geq 3.2$ RMSE & $\geq 90$ & $\mathrm{R}^{2}>0.82$ & 10 to -10 \\
Good & $\mathrm{SD}=2.2$ RMSE-3.2 RMSE & $80 \leq \mathrm{NSE}<90$ & $0.72<\mathrm{R}^{2}<0.82$ & -15 to -25 \\
& & & & and 10 to 15 \\
Satisfactory & $\mathrm{SD}=1.2 \mathrm{RMSE}-2.2 \mathrm{RMSE}$ & $65 \leq \mathrm{NSE}<80$ & $0.62<\mathrm{R}^{2}<0.72$ & 15 to 25 \\
Unsatisfactory & $\mathrm{SD}<1.7$ RMSE & $\mathrm{NSE}<65$ & $\mathrm{R}^{2}<0.62$ & $>25$ and $>-25$ \\
\hline
\end{tabular}

Table 4. Descriptive statistics describing the $\mathrm{S}$ parameter at Patiala-Ki-Rao watershed ${ }^{\S}$.

\begin{tabular}{lcc}
\hline Descriptive Statistics & June to September & October to March \\
\hline Mean $(\mathrm{mm})$ & 47.2 & 35.4 \\
Median $(\mathrm{mm})$ & 35.9 & 30.8 \\
SD & 40.1 & 19.5 \\
CV $(\%)$ & 84.9 & 54.9 \\
\hline
\end{tabular}

\footnotetext{
${ }^{\S}$ S Parameter obtained using equation 5
} 
Sumita Chandel and M. S. Hadda / J. Appl. \& Nat. Sci. 9 (3): 1573 -1581 (2017)

Table 5. Observed and estimated mean runoff corresponding to the mean rainfall per storm in a year at Patiala-Ki-Rao watershed (1982-1999).

\begin{tabular}{|c|c|c|c|c|c|c|c|c|c|c|}
\hline \multirow{2}{*}{ Year } & \multirow{2}{*}{$\begin{array}{c}\text { Mean } \\
\text { rainfall } \\
(\mathrm{mm})\end{array}$} & \multirow{2}{*}{$\begin{array}{l}\text { Observed mean } \\
\text { runoff }(\mathrm{mm})\end{array}$} & \multicolumn{8}{|c|}{ Estimated mean runoff $(\mathrm{mm})$} \\
\hline & & & M1 & M2 & M3 & M4 & M5 & M6 & M7 & M8 \\
\hline 1982 & 44.2 & 26.0 & 15.4 & 20.2 & 21.7 & 27.5 & 25.6 & 16.5 & 20.3 & 11.1 \\
\hline 1983 & 49.5 & 28.5 & 19.9 & 24.7 & 24.5 & 29.9 & 27.8 & 18.2 & 22.8 & 15.5 \\
\hline 1984 & 39.3 & 24.0 & 12.8 & 17.2 & 19.5 & 25.4 & 23.6 & 15.1 & 15.7 & 9.0 \\
\hline 1985 & 40.2 & 23.3 & 12.6 & 17.2 & 19.2 & 24.8 & 23.1 & 14.9 & 18.6 & 8.6 \\
\hline 1986 & 44.5 & 19.5 & 15.7 & 20.5 & 18.1 & 21.5 & 19.7 & 14.1 & 18.4 & 11.4 \\
\hline 1987 & 38.6 & 17.3 & 12.2 & 16.6 & 16.1 & 19.6 & 18.1 & 12.2 & 16.1 & 8.4 \\
\hline 1988 & 85.0 & 42.2 & 48.5 & 54.3 & 39.3 & 43.9 & 40.8 & 27.9 & 41.0 & 43.0 \\
\hline 1989 & 52.6 & 24.0 & 23.6 & 28.3 & 22.3 & 25.9 & 23.9 & 16.8 & 22.6 & 19.5 \\
\hline 1990 & 53.6 & 24.9 & 22.7 & 27.8 & 22.6 & 26.9 & 24.8 & 17.2 & 21.9 & 18.1 \\
\hline 1991 & 45.1 & 17.3 & 16.4 & 21.2 & 17.2 & 19.6 & 17.9 & 13.3 & 17.6 & 12.2 \\
\hline 1992 & 47.8 & 20.4 & 18.3 & 23.2 & 19.4 & 22.5 & 20.7 & 14.9 & 19.8 & 13.9 \\
\hline 1993 & 69.3 & 24.5 & 36.9 & 42.1 & 24.7 & 26.7 & 24.3 & 19.0 & 25.2 & 32.2 \\
\hline 1994 & 57.6 & 25.5 & 27.4 & 32.3 & 23.8 & 27.1 & 24.8 & 18.0 & 23.9 & 23.0 \\
\hline 1995 & 57.8 & 18.3 & 27.3 & 32.2 & 19.0 & 21.2 & 19.2 & 15.2 & 18.9 & 22.9 \\
\hline 1996 & 52.9 & 16.8 & 23.8 & 28.5 & 17.8 & 19.4 & 17.6 & 13.9 & 17.8 & 19.6 \\
\hline 1997 & 67.0 & 16.7 & 33.7 & 39.0 & 19.4 & 20.8 & 18.8 & 15.3 & 19.8 & 28.7 \\
\hline 1998 & 48.8 & 17.3 & 18.9 & 23.8 & 18.0 & 20.4 & 18.7 & 13.4 & 18.2 & 14.4 \\
\hline 1999 & 54.6 & 16.7 & 23.0 & 28.2 & 17.6 & 20.0 & 18.1 & 13.9 & 17.5 & 18.2 \\
\hline
\end{tabular}

Table 6. Comparison of models based on RMSE, NSE, PB and $\mathrm{R}^{2}$ for 217 rainfall-runoff storm events at Patiala-Ki-Rao watershed.

\begin{tabular}{|c|c|c|c|c|c|c|c|c|}
\hline \multirow{2}{*}{ Model (s) } & \multicolumn{4}{|c|}{ S- mean $=47.2$} & \multicolumn{4}{|c|}{ S-median $=35.9$} \\
\hline & RMSE & NSE & PB & $\overline{\mathbf{R}^{2}}$ & RMSE & NSE & PB & $\mathbf{R}^{2}$ \\
\hline M1 & 16.55 & 0.26 & -1.66 & 0.536 & 18.12 & 0.11 & 0.20 & 0.547 \\
\hline M2 & 17.71 & 0.15 & -23.24 & 0.625 & 19.84 & -0.06 & -39.0 & 0.531 \\
\hline M3 & 4.52 & 0.94 & 5.88 & 0.968 & 3.65 & 0.96 & 2.18 & 0.979 \\
\hline M4 & 2.72 & 0.98 & -9.7 & 0.995 & 20.59 & -0.14 & -45.29 & 0.552 \\
\hline M5 & 2.28 & 0.99 & -0.88 & 0.996 & 2.30 & 0.99 & -1.64 & 0.995 \\
\hline M6 & 11.96 & 0.11 & -30.22 & 0.855 & 20.18 & 0.48 & -44.67 & 0.552 \\
\hline M7 & 6.75 & 0.03 & 7.08 & 0.880 & 18.76 & -0.51 & -29.66 & 0.552 \\
\hline M8 & 16.39 & 0.25 & 17.84 & 0.527 & 16.93 & 0.20 & -3.70 & 0.541 \\
\hline
\end{tabular}

Table 7. Performance evaluation of models through ranks (Scores) by using mean S parameter.

\begin{tabular}{cccccccccc}
\hline & \multicolumn{1}{c}{ S-mean=47.2 } \\
\cline { 2 - 10 } & $\begin{array}{c}\text { RMSE } \\
(\mathbf{m m})\end{array}$ & $\begin{array}{c}\text { Rank } \\
\text { (Score) }\end{array}$ & NSE & $\begin{array}{c}\text { Rank } \\
\text { (Score) }\end{array}$ & PB & $\begin{array}{c}\text { Rank } \\
\text { (Score) }\end{array}$ & R $^{\mathbf{2}}$ & $\begin{array}{c}\text { Rank } \\
\text { (Score) }\end{array}$ & $\begin{array}{c}\text { Total } \\
\text { (Score) }\end{array}$ \\
\hline M1 & 16.55 & $7(2)$ & 0.26 & $4(5)$ & -1.66 & $2(7)$ & 0.536 & $8(1)$ & 15 \\
M2 & 17.71 & $8(1)$ & 0.15 & $6(3)$ & -23.24 & $7(2)$ & 0.625 & $6(3)$ & 9 \\
M3 & 4.52 & $3(6)$ & 0.94 & $3(6)$ & 5.88 & $3(6)$ & 0.968 & $3(6)$ & 24 \\
M4 & 2.72 & $2(7)$ & 0.98 & $2(7)$ & -9.7 & $4(5)$ & 0.995 & $2(7)$ & 26 \\
M5 & 2.28 & $1(8)$ & 0.99 & $1(8)$ & -0.88 & $1(8)$ & 0.996 & $1(8)$ & 32 \\
M6 & 11.96 & $5(4)$ & 0.11 & $7(2)$ & -30.22 & $8(1)$ & 0.855 & $5(4)$ & 11 \\
M7 & 6.75 & $4(5)$ & 0.03 & $8(1)$ & 7.08 & $5(4)$ & 0.88 & $4(5)$ & 15 \\
M8 & 16.39 & $6(3)$ & 0.25 & $5(4)$ & 17.84 & $6(3)$ & 0.527 & $7(2)$ & 13 \\
\hline
\end{tabular}

Performance evaluation: Based on the RMSE values, model M5 performed best with the minimum RMSE (2.3)by using mean $\mathrm{S}$ parameter (47.2), followed by M4 (2.7), M3 (4.5), M7 (6.8), M6 (11.9), M8 (16.4), M1 (16.6), M2 (17.7)(Table 6). The similar, trend was observed with median $\mathrm{S}$ parameter in evaluating the performance of different models. The models M1 and M8 showed unsatisfactory results while, M2, M3, M4, M5, M6 and M7 showed very good results as per the rating criteria given in Table 3 (Ritter and Munozcarpena, 2013). This might be attributed to the rainfall characteristics viz., rainfall intensity and duration 
Sumita Chandel and M. S. Hadda / J. Appl. \& Nat. Sci. 9 (3): 1573 -1581 (2017)

Table 8. Performance evaluation of models through ranks (Scores) by using median S parameter.

\begin{tabular}{ccccccccccc}
\hline Model & RMSE & $\begin{array}{c}\text { Rank } \\
\text { (Score) }\end{array}$ & NSE & $\begin{array}{c}\text { Rank } \\
\text { (Score) }\end{array}$ & PB & $\begin{array}{c}\text { Rank } \\
\text { (Score) }\end{array}$ & R $^{2}$ & $\begin{array}{c}\text { Rank } \\
\text { (Score) }\end{array}$ & $\begin{array}{c}\text { Rank } \\
\text { (Score) }\end{array}$ & Total \\
\hline M1 & 18.1 & $4(5)$ & 0.11 & $7(2)$ & $\mathbf{0 . 2}$ & $1(8)$ & 0.547 & $3(6)$ & 6 & 21 \\
M2 & 19.8 & $6(3)$ & -0.06 & $8(1)$ & -39 & $6(3)$ & 0.531 & $6(3)$ & 3 & 10 \\
M3 & 3.7 & $2(7)$ & 0.96 & $2(7)$ & 2.18 & $3(6)$ & 0.979 & $2(7)$ & 7 & 27 \\
M4 & 20.6 & $8(1)$ & -0.14 & $6(3)$ & -45.29 & $8(1)$ & 0.552 & $4(5)$ & 5 & 10 \\
M5 & 2.3 & $1(8)$ & 0.99 & $1(8)$ & -1.64 & $2(7)$ & 0.995 & $1(8)$ & 8 & 31 \\
M6 & 20.2 & $7(2)$ & 0.48 & $4(5)$ & -44.67 & $7(2)$ & 0.552 & $4(5)$ & 5 & 14 \\
M7 & 18.76 & $5(4)$ & -0.51 & $3(6)$ & -29.66 & $5(4)$ & 0.552 & $4(5)$ & 5 & 19 \\
M8 & 16.93 & $3(6)$ & 0.2 & $5(4)$ & -3.7 & $4(4)$ & 0.541 & $5(4)$ & 4 & 19 \\
\hline
\end{tabular}

Table 9. Regression equation for estimated and observed runoff through different modelswith intercept, slope and coefficient of determination.

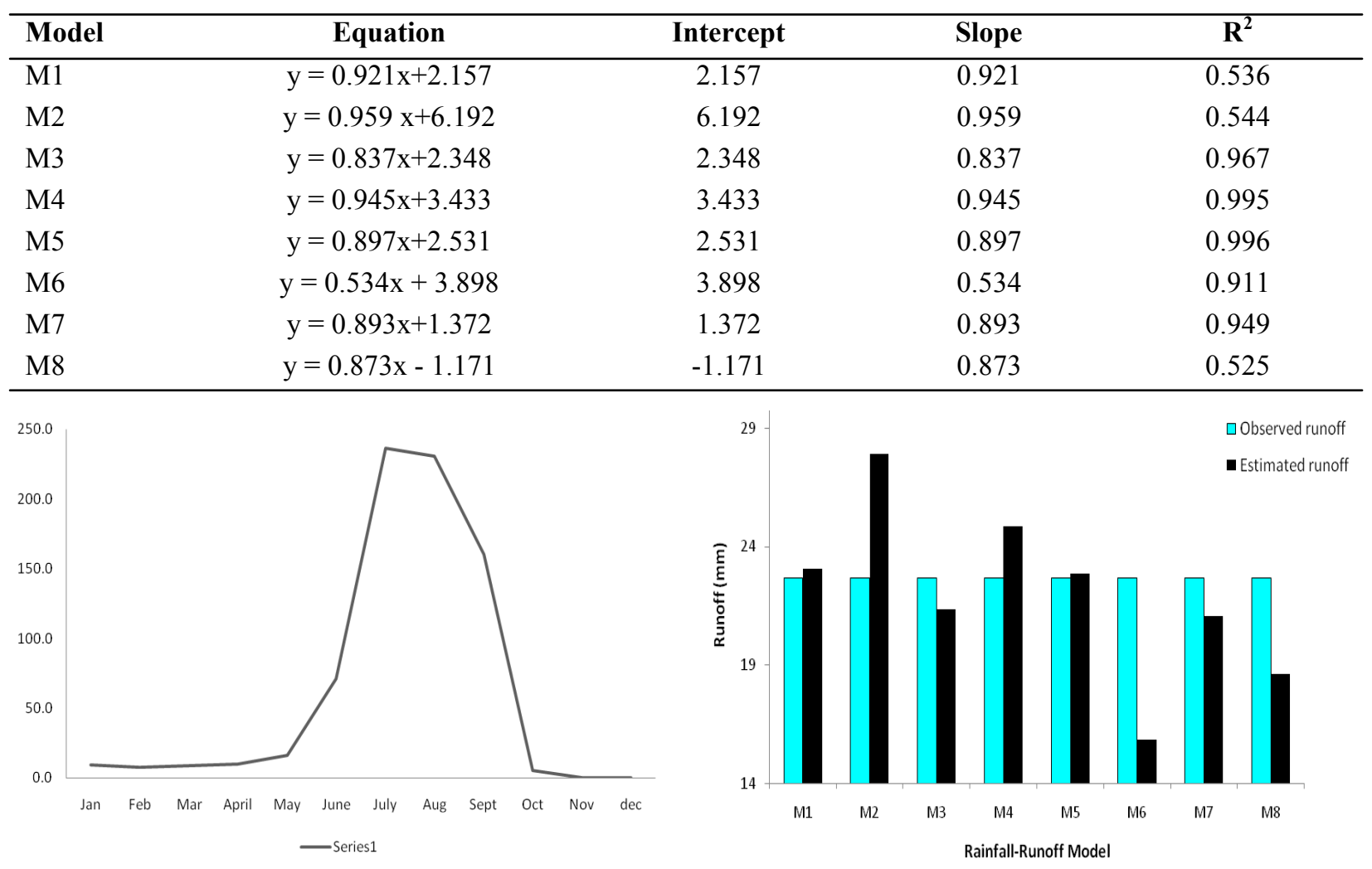

Fig. 2. Monthly distribution of rainfall $(\mathrm{mm})$ over the years (1982 - 1999) at Patiala-Ki-Rao watershed

which were not considered in the original SCS-CN method. However, in case of M5 model, initial abstraction (Ia) was modified by considering its dependence on surface conditions, rainfall and prior five day rainfall $\left(\mathrm{P}_{5}\right)$. The current study's findings are in agreement with the Feyereisen et. al. (2008), wherein it was evident that the proposed Ia provided better results in the South East coastal plains of Georgiathan that in the original NRCS model as well as in other modifications. Azmal et al. (2016) proposed that the modification in Ia (M5 model) showed good results, with $26.9,20.2,26.2$ and 16.7 per cent im-

Fig. 3. Comparision of observed and estimated runoff from the year 1982 to 1999 through different models.

provement in the mean RMSE in watersheds of South Korea.

The maximum value of the NSE in Patiala-Ki-Rao watershed is indicated by M5 ie 0.99 , when, mean of the S parameter was used, followed by M4 (0.98), M3 (0.94), M1 (0.26), M8 (0.25), M2 (0.15), M6 (0.11) and M7 (0.03). The model M5 performed best for the estimation of the surface runoff in the study area. Similar results were obtained when median $\mathrm{S}$ parameter was used. The NSE value computed by the model greater than 0.65 is considered good (Moriasi et. al., 2007). Using this criteria, the model M5 =M4 were 
Sumita Chandel and M. S. Hadda / J. Appl. \& Nat. Sci. 9 (3): 1573 -1581 (2017)
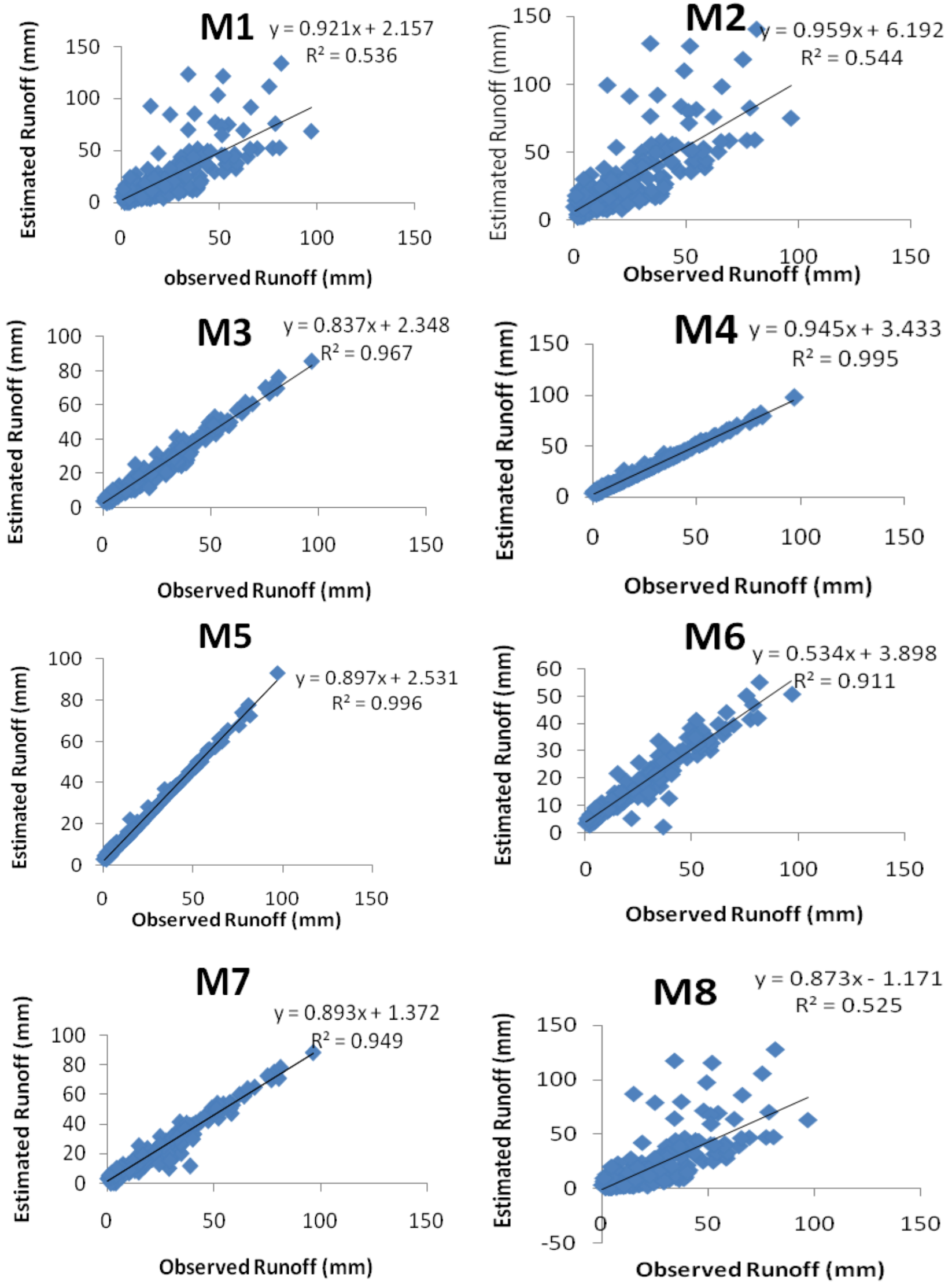

Fig. 4. Relationship between observed and estimated runoff through different models M1-M8 
equal and showed the better performance over the other evaluated models in the watershed. This indicated that the Ia modifications improves the efficiency of the rainfall-runoff model.

Effectiveness of the suggested models can be further tested by comparing the observed and estimated runoff on the basis of coefficient of determination $\left(\mathrm{R}^{2}\right)$. A hydrological model is considered good if $\mathrm{R}^{2}$ value is greater than 0.82 (Diaz-Tamirez et al., 2011). The M5 model better estimated the surface runoff by using both mean and median value of the $\mathrm{S}$ parameter. The highest coefficient of determination $\left(\mathrm{R}^{2}\right)$ ie 0.996 was found in M5, followed by M4 (0.995), M3 (0.968), M7 (0.880), M6 (0.855), M2 (0.625), M1 (0.536) and M8 (0.527) when runoff was computed by mean of $\mathrm{S}$ parameter. Similarly, same pattern was observed when runoff was computed by using median (0.35) $\mathrm{S}$ parameter. Highest $\mathrm{R}^{2}$ value was found in M5 (0.995), followed by M3 (0.979), M4, M6, M7 (0.552), M1 (0.547), M8 (0.541) and M2 (0.531). It further, indicated that the models M5 and M6 performed betterin estimating the surface runoff in the watershed. The model M5 showed better performance with PB value as -0.88 and -1.64 by using mean and median of the $\mathrm{S}$ parameter in estimating the surface runoff, respectively in the Patiala-Ki-Rao watershed (Table 5). However, the models, M6 and M7 performed poorly in estimating the surface runoff in the watershed. The model M5 performed best in estimating the surface runoff due to the proposed modifications in the initial abstraction. Contrary to this,SCS-CN and other models did not consider these modifications. In addition to this,model's performance can also be assessed visually on the basis of scattered plot of the observed and estimated surface runoff (Fig. 3). The model M5 showed better agreement between the observed and estimated runoff as indicated with higher slope (0.897) and higher coefficient of determination $\left(\mathrm{R}^{2}=0.996\right)$ and the same was indicated in Table 9.

The performance evaluation of models based on ranks (Scores) by using mean $\mathrm{S}$ parameter is given in Table 7. The highest score was indicated by the model M5 (32) followed by the M4 (26) and M3 (24). The models M1, M2, M6, M7 and M8 didn't perform well when mean (47.2) of the $\mathrm{S}$ parameter was used for estimating the surface runoff.The models performance order was of the kind: $\mathrm{M} 5>\mathrm{M} 4>\mathrm{M} 3>\mathrm{M} 7=\mathrm{M} 1>\mathrm{M} 8>\mathrm{M} 6>\mathrm{M} 2$. The Performance evaluation of models through ranks (Scores) by using median $\mathrm{S}$ parameter is shown in Table 8 . The overall highest score was obtained in M5 (31) followed by M3 (27). The performance evaluation of the models from best to worst (left to right) followed the trend: $\mathrm{M} 5>\mathrm{M} 3>\mathrm{M} 1>\mathrm{M} 7>\mathrm{M} 8>\mathrm{M} 6>\mathrm{M} 2=\mathrm{M} 4$.

The comparision of observed and estimated mean runoff per storm in the years 1982 to 1999 is shown in Fig. 3. The M5 model performed best over the other evaluated models which either overestimate or underestimate runoff over the observed runoff. This might be attributed of maintaing its simplicity and using the relevant information on the parameters from the watershed such as prior 5- days rainfall, potential maximum retention, and magnitude of rainfall in events etc. Thus, a new non-linear relationship existed for the variable initial abstraction (Ia) to prevent the fluctuations in runoff estimation and improved the performance of NRCS model in estimating the runoff quite accurately (Wang et al., 2015; Azmal et al., 2016).

The relationship between estimated and observed runoff through different models M1-M8 and their regression equations obtained are given in Fig. 4 and Table 9. Of the evaluated models, the $\mathrm{R}^{2}$ obtained was maximum in M5=M4 $(0.995 ; 0.996)$ and least in M8 (0.525). The model M8 although utilised the concept of time delay factor and water budget equation on daily rainstorm event basis. This model M8 predicted the runoff for low to moderate amounts of rainfall accurately but required modifications at higher amounts of rainfall.

\section{Conclusion}

The estimation of surface runoff using rainfall-runoff models in the Patiala-Ki-Rao watershed indicated that the proposed modified initial abstraction ie model M5 performed best. Because it is dependent not only on maximum potential retention, as assumed originally in model M1 $(\mathrm{Ia}=0.2 \mathrm{~S})$ and by model M2 $(\mathrm{Ia}=0.05 \mathrm{~S})$, but also depends on the storm size and the prior 5-days rainfall. The original NRCS model ie M1 seems to be less accurate, whereas the modified NRCS model M5 significantly improved the runoff estimation. It is in better agreement with the observed runoff, which was also confirmed by other employed goodness of fit procedures through the models. So, in the hydrological design work, if rainfall and runoff measurements are available, $\mathrm{S}$ parameter can be calibrated from this data and then employed for the estimation of runoff. Further, the results of the study suggest in evaluating the performance of NRCS model M5 in other treated micro-watersheds at Patiala-Ki-Rao, Punjab, over the control.

\section{ACKNOWLEDGEMENTS}

The authors express sincere thanks to Dr HS Sur, Ex-Sr Consultant Planning Commission, GOI for providing daily measured rainfall and runoff data for Patiala- Ki- Rao watershed, SAS Nagar and the financial help provided by the department of Science and Technology, GOI in the form of INSPIRE fellowship during the doctoral program to the first author.

\section{REFERENCES}

Azmal, M. and Kim, T. W. (2015). Quantification excess storm water using SCS-CN based rainfall runoff models 
and different curve number determination methods. $J$. Irrig. Civil Eng., 141(3):04014058.

Azmal,M., Ahn, J. H. and Kim, T. W.(2016). Excess storm water quantification in ungauged watershed using an event based modified NRCS model. Water Resour. Manage., 30:1433-1448.

Cazier, D. J.and Hawkins R. H. (1984). Regional application of the curve number method. Water today and tomorrow. Proc. ASCE Irrigation and Drainage Division Special Conf., ASCE, New York, 710.

Diaz-Ramirez, J. N., McAnally, W. H. and Martin, J. L. (2011). Analysis of hydrological processes applying the HSPF model in selected watersheds in Alabama, Mississippi, and Puerto Rico. Appl. Eng. Agri. 27 (6):937-954.

Feyereisen, G. W., Strickland, T. C., bosch, D. D., Truman, C. C., Sheridan, J. M. and Potter T. L. (2008). Curve number estimated for conventional and conservation tillage in the Southeast Coastal Plain. J. Soil Water Conserv. 63 (3): 120-128.

Hadda, M. S., Khera, K. S.and Kukal, S. S. (2000). Soil and water conservation practices and productivity in northern-western submontane tract of India. Indian J. Soil Cons. 28: 187-92.

Hadda, M. S., Sur, H. S. and Sandhu, B. S.(2001). Runoff and soil loss in foothills of Shivaliks. Indian J. Soil Cons. 29: 14-17.

Hadda, M. S., Sandhu B. S. Singh, T. (2002). A runoff model for micro-watershed in North-Western tract of India. $J$. Punjab Acad. Sci. 1:1-8.

Heggen, R. J. (2001). Normalized antecedent precipitation index. J. Hydrol. Eng., ASCE, 6(5): 377-381.

Jain, M. K., Mishra, S. K., Suresh Babu, P.and Venugopal, K. (2006). On the Ia-S relation of the SCS-CN method. Nordic Hydrol.37 (3):261-275.

Lin, G. F. and Wang, C.M. (2007). A nonlinear rainfallrunoff model embedded with an automated calibration method - Part 1: The model, J Hydrol. 341: 186-195.

Meher, Janhabi (2014). Rainfall and runoff estimation using hydrological models and ANN techniques. PhD Thesis. Civil Engineering. National Institute of Civil Engineering, Rourkela.

Mishra, S. K., Jain, M. K., Pandey, R. P. and Singh, V. P. (2005). Catchment area-based evaluation of the AMCDependent SCS-CN-inspired rainfall-runoff models Hydrol. Pro. 19(14). 2701-2718.

Moriasi, D. N., Arnold, J. G., Van Liew, M. W., Binger, R.
L., Harmel, R. D. and Veith, T. ( 2007). Model evaluation guidelines for systematic quantification of accuracy in watershed simulations. Trans ASABE, 50 (3):885-900.

Papanicolaou, A.N., Elhakeem, M., Krallis, G., Prakash, S.and Edinger, J. (2008). Sediment transport modeling review-current and future developments. J. Hydrol. Eng. 134(1): 1-14.

Ponce, V. M. and Hawkins, R. H. (1996). Runoff curve number: has it reached maturity? J. Hydrol. Eng.1: 11-19.

Ritter, A. and Munoz-carpena R.(2013). Performance evaluation of hydrological models: Statistical significance for reducing subjectivity in goodness of fit assessment. $J$. Hydrol. 480: 33-45.

SCS, (1972).National Engineering Handbook, Section 4, Hydrology. Soil Conservation Service, US Department of Agriculture, Washigton DC

Shi, Z. H., Chen, L. D., Fang, N. F., Qin, D. F. and Cai, C. F. (2009). Research on the SCS-CN initial abstraction ratio using rainfall-runoff event analysis in the Three Gorges Area, China. Catena, 77 (1): 1-7.

Singh, M. (2014). Simulating rainfall changes effects on runoff and soil erosion in submontane Punjab. M.Sc. Thesis, Punjab Agricultural University, Ludhiana.

Soil Survey Staff. (1975). 'Soil Taxonomy'. Agriculture Handbook 436. (Soil Conservation Service, USDA: Washington, D.C.)

Thornthwaite, C. W. (1948). An approach towards a rational classification of climate. Reviews of Geophysics, 38: 55 $-94$.

Vaezi, A. R., Bahrami, H. A., Sadeghi S. H. R. and Mahdian M. H. (2010). Modelling relationship between runoff and soil properties in dry-farming lands, NW Iran.Hydrol. sys. Sci. Dis. 7: 2577-2607.

Wang, D., Bao, L. Q., Wang, M. and Zhang, W. (2015). Application of SCS-CN Model in Runoff Estimation. International Symposium on Material, Energy and Environment Engineering: 50-54.

Woodward, D. E., Hawkins, R. H., Jiang, R., Hjelmfelt, Jr., A. T., Van Mullem., J. A. and Quan Q.D. (2003). "Runoff curve number method: Examination of the initial abstraction ratio." Proc., World Water and Environmental Resources Congress, 1-10.

USDA-NRCS (US Department of Agriculture, Natural Resources Conservation Service) (2004). 'Hydrology' National Engineering Handbook, Supplement A, Section 4. Soil Conservation Service, USDA, Washington, DC. 